\title{
Complications of invasive intracranial pressure monitoring devices in neurocritical care
}

\author{
Samon Tavakoli, MD, ${ }^{1}$ Geoffrey Peitz, MD, ${ }^{1}$ William Ares, MD, ${ }^{2}$ Shaheryar Hafeez, MD, ${ }^{1}$ and \\ Ramesh Grandhi, MD ${ }^{1}$
}

1Department of Neurosurgery, University of Texas Health San Antonio, Texas; and 2Department of Neurosurgery, University of Pittsburgh, Pennsylvania

\begin{abstract}
Intracranial pressure monitoring devices have become the standard of care for the management of patients with pathologies associated with intracranial hypertension. Given the importance of invasive intracranial monitoring devices in the modern neurointensive care setting, gaining a thorough understanding of the potential complications related to device placement-and misplacement-is crucial. The increased prevalence of intracranial pressure monitoring as a management tool for neurosurgical patients has led to the publication of a plethora of papers regarding their indications and complications. The authors aim to provide a concise review of key contemporary articles in the literature concerning important complications with the hope of elucidating practices that improve outcomes for neurocritically ill patients.

https://thejns.org/doi/abs/10.3171/2017.8.FOCUS17450
\end{abstract}

KEY WORDS intracranial monitoring; infection; hemorrhage; complications; considerations; neurocritical care

I NTRACRANIAL pressure (ICP) monitoring and external CSF drainage are fundamental to the management of neurosurgical patients in the critical care setting, and current methods have evolved considerably since the early days of neurosurgery. The first documented ventricular cannulation and drainage was performed in 1744 when Claude-Nicolas Le Cat treated a child with congenital hydrocephalus by draining ventricular CSF via a specially designed wick for 5 days, until the patient died (Fig. 1). ${ }^{54}$ During the 18th and 19th centuries, the techniques and materials for ventriculostomy improved, and the indications expanded. In 1898, Fedor Krause described the use of ventricular drainage perioperatively in posterior fossa surgery, ${ }^{52}$ and in 1918, Walter Dandy described ventriculography after injecting air into the ventricles. ${ }^{12}$ By the early 20th century, manometry was incorporated, allowing ICP measurement. External ventricular drains (EVDs) were being used for continuous ICP monitoring in patients with brain tumors by the 1960s and for patients with subarachnoid hemorrhage (SAH) and patients with traumatic brain injury (TBI) by the 1980s. ${ }^{54}$ Currently, the Brain Trauma Foundation 4th edition guidelines provide a Level IIB recommendation for the use of ICP monitoring in the management of patients with severe TBI to reduce in-hospital and 2-week postinjury mortality. ${ }^{9}$

Technical difficulties and complications associated with ventricular catheterization led to the development of fiberoptic and miniature strain-gauge sensors that could be placed in the subdural space, parenchyma, or ventricle for ICP monitoring. The reliability and efficacy of such devices were studied during the 1990s and found to be reasonably accurate compared with EVDs. ${ }^{23,24,26}$ Although EVDs remain the gold standard in ICP monitoring due to their ability to be zeroed in vivo as well as their ability to drain CSF, intraparenchymal and subdural monitors are preferred in some cases or by some providers because of the latter's comparative ease of placement and perceived lower risk of complications. Herein, the types and frequencies of complications for EVDs and ICP monitors (ICPMs) are discussed.

\section{Complications of EVDs and ICPMs Infection Rates}

Ventriculostomy-associated infections (VAIs), or ventriculostomy-related infections, are the most common complication associated with placement of EVDs; the rate of VAIs was estimated in one meta-analysis to be $0 \%-22 \%$, with an average rate of $8.8 \%$ (Table 1)..$^{39,42,48}$ In a recent retrospective study of 288 patients comparing complication rates in EVDs and ICPMs, Dimitriou et al. found rates of infection to be $9.2 \%$ and $0.8 \%$, respectively. In ad-

ABBREVIATIONS AI = antibiotic impregnated; DVT = deep venous thrombosis; EVD = external ventricular drain; ICP = intracranial pressure; ICPM = ICP monitor; ICU = intensive care unit; OR = operating room; $\mathrm{SAH}=$ subarachnoid hemorrhage; TBI = traumatic brain injury; VAI = ventriculostomy-associated infection; VTE = venous thromboembolism.

SUBMITTED July 3, 2017. ACCEPTED August 15, 2017.

INCLUDE WHEN CITING DOI: 10.3171/2017.8.FOCUS17450. 


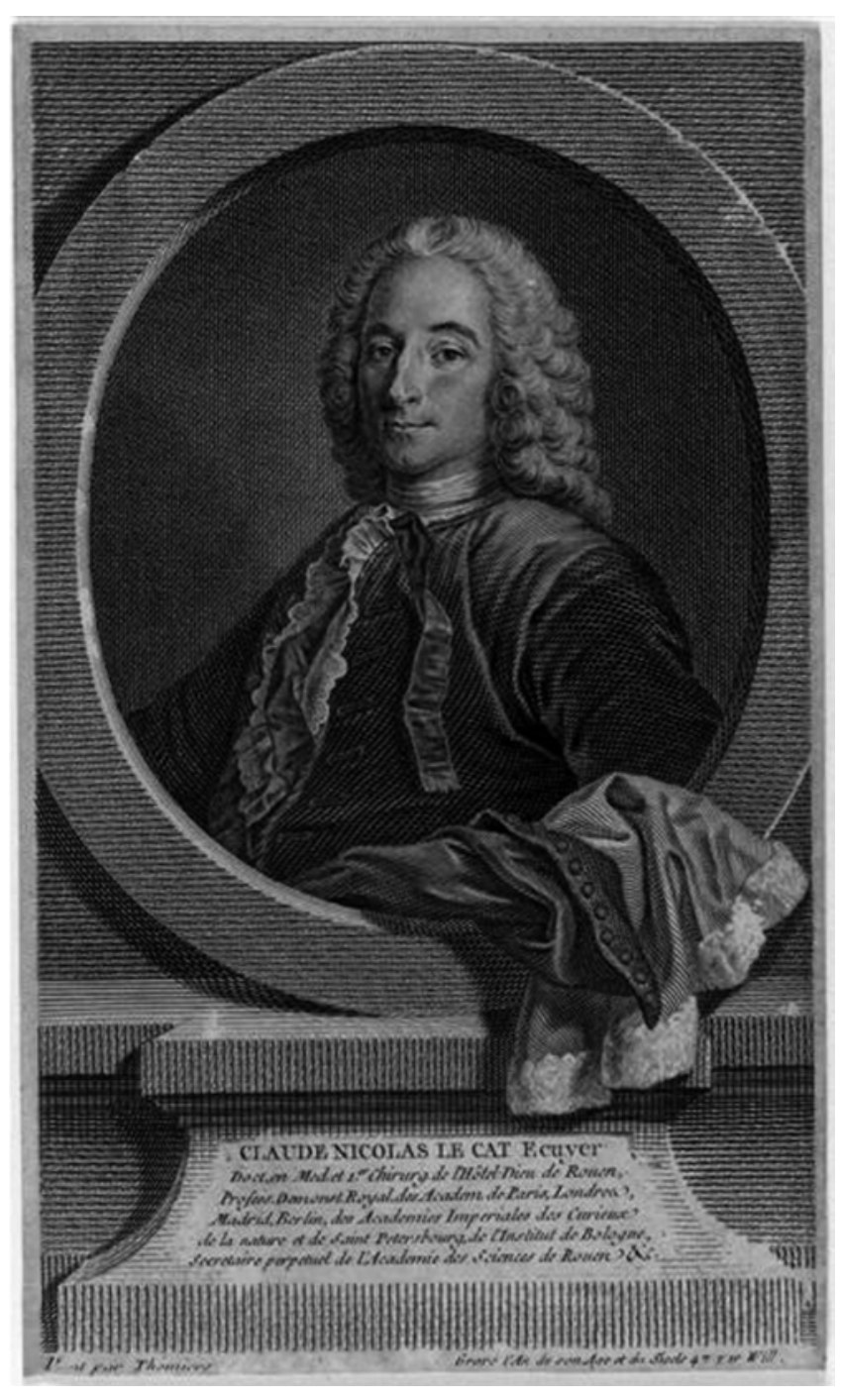

FIG. 1. Portrait of Claude-Nicolas Le Cat (1700-1768), French surgeon who performed the first recorded ventriculostomy for drainage of CSF. Public domain.

dition, they found that infection rates were increased in the presence of SAH (9.4\%), intraventricular hemorrhage (8.6\%), and concomitant catheters $(3.5 \%)$, with the greatest incidence occurring between the 5th and 11th day after placement. ${ }^{16}$

With regard to ICPMs, Guyot et al. reported no infections in 229 patients who underwent placement of Camino (Integra LifeSciences) intraparenchymal ICP monitors; ${ }^{27}$ in addition, rates of infection with concurrent placement of EVDs and ICPMs seem to be similar to those of EVD placement alone. ${ }^{2,5}$ To date, the majority of studies reporting VAI rates have been in TBI-predominant patient populations; however, in a large retrospective analysis of 116,813 patients with aneurysmal SAH, $32.9 \%$ were managed with EVDs, with a mean annual rate of infection of $7.3 \%{ }^{48}$

In a similar retrospective analysis of the Nationwide Inpatient Sample of 34,238 patients with spontaneous intracranial hemorrhage, a subset of patients with VAIs had an overall significant increase in the rate of inpatient mortality, length of stay, and cost of care. Predictors of VAI in their analysis included increased age, male sex, presence of medical comorbidities or systemic infections, and longer hospital length of stay. ${ }^{44} \mathrm{VAI}$ is an important controllable risk factor that can significantly affect patient outcomes.

Although infection is the most common complication associated with invasive intracranial monitor placement, there is no consensus-accepted standard definition for VAI, which limits the study, surveillance, and comparison of practices. In a literature search performed by Lewis et al., 16 different definitions for VAI were found, 9 of which were subjective. After applying definitions to a test cohort, they found that the frequency of infection ranged from $22 \%$ to $94 \% .{ }^{38}$ To further illustrate the variability in defining VAIs, one study applied criteria from Honda et al., Gozal et al., and Citerio et al. to a retrospective series and found that rates of infection based on each authors' criteria were $60 \%, 56 \%$, and $23 \%$, respectively. $11,25,30,51$

In 2014, Gozal et al. proposed a standardized definition of VAIs as a positive CSF culture in a patient with a ventriculostomy catheter and one of the following: a fever $>101.5^{\circ} \mathrm{F}$, a CSF glucose level $<50 \mathrm{mg} / \mathrm{dl}$, or a CSF glucose level $<50 \%$ of any serum glucose drawn within 24 hours of CSF sample. ${ }^{25}$ Most recently, the 2017 Infectious Diseases Society of America guidelines on healthcare-associated ventriculitis and meningitis did not give a definition of VAI, but provided guidance for when clinical suspicion prompts CSF sampling for infection. CSF pleocytosis with a positive culture and infectious symptoms are indicative of VAI, a strong recommendation with a high level of evidence. CSF cultures that grow Staphylococcus aureus, aerobic gram-negative bacilli, and fungal pathogens are likely to represent true infection, whereas minimal growth of coagulase-negative Staphylococcus in the setting of normal CSF and lack of a fever are probably indicative of a contaminant. Furthermore, there is lowquality evidence for hypoglycorrhachia with elevated CSF protein representing infection. ${ }^{58}$

In a 2017 survey of AANS members regarding EVD infection rates, respondents reported infection rates ranging from $1 \%$ to $3 \%$, and $42.7 \%$ reported the use of institutional protocols, although almost 33\% admitted incomplete adherence to protocols. ${ }^{4}$ This survey highlights that attitudes and perceptions of catheter-related infection are grossly underestimated by individual clinicians and that there exists significant heterogeneity in practice and a lack of compliance with institutional protocols.

There is insufficient evidence regarding the risks and benefits of prophylactic antibiotic administration with invasive intracranial monitoring. Multiple retrospective studies comparing the administration of prophylactic antibiotics periprocedurally or for the duration of monitoring have not been able to demonstrate a decreased risk of VAIs compared with patients who did not receive antibiotics. ${ }^{32,50,55}$ In fact, Jacobs and Westerband found higher rates of sepsis and pneumonia and Stoikes et al. found a higher incidence of multidrug-resistant pathogens in ventilatorassociated pneumonia and bloodstream infections in patients to whom antibiotics were administered prophylactically. ${ }^{32,50,55}$ Another randomized trial, which compared 
TABLE 1. VAI rates

\begin{tabular}{|c|c|c|c|c|c|}
\hline Authors \& Year & Study Design & No. of Cases & Pathology, No. of Cases & Infection Rate & Comments \\
\hline Dimitriou et al., 2016 & Retrospective & 288 & TBI, 180; vascular, 108 & EVD 9.2\%; ICPM 0.8\% & \\
\hline Guyot et al., 1998 & Retrospective & 536 & Undifferentiated & $\begin{array}{l}\text { EVD } 7.3 \% ; \text { ICPM } 0.0 \% \\
\text { other devices } 0.0 \%\end{array}$ & \\
\hline Park et al., 2004 & Retrospective & 595 & $\begin{array}{l}\text { TBI, 75; vascular, } 397 ; \\
\text { tumor, 102; other, } 21\end{array}$ & EVD $8.6 \%$ & VAI rate increased until Day 4 \\
\hline Holloway et al., 1996 & Retrospective & 584 & TBI & EVD $10.4 \%$ & VAI rate increased until Day 10 \\
\hline Mayhall et al., 1984 & Prospective & 172 & Undifferentiated & EVD $8.9 \%$ & $\begin{array}{l}\text { VAI rates at Days } 8,10, \& 11 \text { were } \\
21 \%, 37 \%, \& 42 \% \text {, respectively }\end{array}$ \\
\hline Lozier et al., 2002 & Meta-analysis & 5733 & Undifferentiated & EVD 8.8\% & VAl rate $0 \%-22 \%$ \\
\hline Poblete et al., 2017 & Multicenter retrospective & 38,431 & Aneurysmal SAH & Annual VAI rate $7.3 \%$ & \\
\hline
\end{tabular}

prophylactic trimethoprim-sulfamethoxazole for the duration of monitoring with placebo in patients undergoing ventriculostomy, found no significant difference in VAI rates. ${ }^{8}$ Thus, there is limited evidence for the use of periprocedural antibiotics for VAI prophylaxis and, perhaps more worrisome, an increased risk of developing multidrug-resistant pathogens and double the rate of systemic infectious complications ( $0.7 \%$ vs $1.4 \%$ per patient) ${ }^{50}$

The use of systemic antibiotics for the duration of monitoring may be more harmful than helpful; however, the use of antibiotic-impregnated (AI) catheters seems to be beneficial (Table 2). Zabramski et al. randomly assigned patients to receive an AI-EVD $(n=149)$ or standard silicon catheters $(n=139)$ and found a 7-fold reduction in VAIs as defined by positive CSF culture in patients in whom AI catheters were used compared with the standard catheter group $(1.3 \%$ vs $9.4 \% ; \mathrm{p}=0.002)$. In addition, they demonstrated that AI-EVDs were half as likely to become colonized with pathogens $(17.9 \%$ vs $36.7 \%$; $\mathrm{p}=0.0012) .{ }^{59}$
Conversely, in another large, prospective randomized trial comparing 176 patients with AI-EVDs with 181 patients with standard ventricular catheters, there was no significant difference in the rate of VAIs or number of patients treated for suspected VAI. ${ }^{49}$ Furthermore, Harrop et al. described a prospective cohort study in which the introduction of AI-EVDs decreased the VAI rate from $8.2 \%$ to $1 \%{ }^{28}$ Interestingly, the VAI rate increased to $7.6 \%$ when the institution reverted to standard catheters due to technical problems with the AI-EVDs; however, when the AI-EVDs were reintroduced, the VAI rate decreased to $0.9 \% .^{28}$

Based on the available evidence and selected studies above, there seems to be a trend toward decreased rates of VAI with AI-EVDs. To this end, the 2016 Neurocritical Care Society consensus statement on neuromonitoring recommended the use of AI-EVDs, and the Brain Trauma Foundation 4th edition guidelines provided a Level III recommendation for the use of AI-EVDs to prevent VAIs., ${ }^{9,19}$

\section{TABLE 2. VAI rates with antibiotic prophylaxis or Al-EVDs}

\begin{tabular}{|c|c|c|c|c|c|}
\hline Authors \& Year & Study Design & $\begin{array}{l}\text { No. of } \\
\text { Cases }\end{array}$ & Pathology, No. of Cases & VAI Rate & Comments \\
\hline $\begin{array}{l}\text { Jacobs \& West- } \\
\text { erband, } 1998\end{array}$ & Retrospective & 30 & $\mathrm{TBI}$ & $0 \%$ in both cohorts & $\begin{array}{l}\text { Increased rates of sepsis }(78.6 \% \text { vs } 31.3 \%) \& \\
\text { pneumonia }(57.1 \% \text { vs } 18.8 \%)\end{array}$ \\
\hline $\begin{array}{l}\text { Rebuck et al., } \\
2000\end{array}$ & Retrospective & 215 & $\begin{array}{l}\text { Intracranial hemorrhage, } \\
\text { 95; TBI, 58; aneurys- } \\
\text { mal SAH, 25; other, } 37\end{array}$ & $7.4 \%$ overall & $\begin{array}{l}62.5 \% \text { of patients w/ VAI received prophylactic } \\
\text { antibiotics; increased risk w/ EVD, CSF leak, } \\
\text { non-CNS infection, duration }>5 \text { days, }>1 \text { ICPM }\end{array}$ \\
\hline $\begin{array}{l}\text { Stoikes et al., } \\
2008\end{array}$ & Retrospective & 155 & $\mathrm{TBI}$ & $\begin{array}{l}0 \% \text { w/out antibiotic } \\
\text { prophylaxis vs } 2.4 \% \mathrm{w} / \\
\text { antibiotic prophylaxis }\end{array}$ & $\begin{array}{l}\text { Rates of infectious complications ( } 0.7 \% \text { vs } 1.4 \%) \\
\text { \& infections secondary to multidrug-resistant } \\
\text { pathogens ( } 0.03 \text { vs } 0.33 \text { per patient) were great- } \\
\text { er in patients receiving prophylactic antibiotics }\end{array}$ \\
\hline Blomstedt, 1985 & Randomized & 122 & $\begin{array}{l}\text { Tumor, 53; low-pressure } \\
\text { hydrocephalus, 29; } \\
\text { vascular, 18; other, } 22\end{array}$ & $\begin{array}{l}3.7 \% \text { w/out antibiotic } \\
\text { prophylaxis vs } 4 \% \mathrm{w} / \\
\text { antibiotic prophylaxis }\end{array}$ & \\
\hline $\begin{array}{l}\text { Harrop et al., } \\
22010\end{array}$ & Prospective & 1961 & & $\begin{array}{l}1 \% \text { w/ Al-EVD (catheter A) } \\
\text { vs } 8.2 \% \text { w/out Al-EVD }\end{array}$ & $0.9 \%$ w/ Al-EVD (catheter B) vs $7.6 \%$ w/out Al-EVD \\
\hline $\begin{array}{l}\text { Pople et al., } \\
2012\end{array}$ & Randomized & 357 & & $\begin{array}{l}2.3 \% \text { w/ Al-EVD vs } 2.8 \% \\
\text { w/ standard catheter }\end{array}$ & $\begin{array}{l}\text { Duration of time to infection ( } 8.8 \pm 6.1 \text { vs } 4.6 \pm 4.2 \\
\text { days) in Al-EVD vs standard catheter }\end{array}$ \\
\hline $\begin{array}{l}\text { Zabramski et al., } \\
\quad 2003\end{array}$ & Randomized & 288 & & $\begin{array}{c}1.3 \% \text { w/ Al-EVD vs } 9.4 \% \\
\text { w/ standard catheter }\end{array}$ & $\begin{array}{l}\text { Rates of EVD colonization were } 17.9 \% \text { vs } 36.7 \% \text { in } \\
\text { AI-EVD vs standard catheter, respectively }\end{array}$ \\
\hline
\end{tabular}


Specific protocols designed to decrease infection rates for EVDs and ICPMs are being used more frequently in institutions and critical care settings around the world. In a prospective study, Chatzi et al. introduced a protocol that included education of surrounding personnel regarding infection control, meticulous handling of the EVD, minimization of CSF sampling from the EVD, and routine replacement of the catheter on Day 7. After initiation of the protocol, VAI rates dropped from $28 \%$ in the preintervention period to $10.5 \%$. Notably, patients who were diagnosed with VAIs had a mean length of stay of 44.4 days compared with 20 days in patients who did not experience a VAI ( $p<0.001)$, highlighting the significant benefit from a systems, cost, and resources-based perspective of initiating institution-specific protocols. ${ }^{10}$ Similarly, protocols instituted by Dasic et al. included training of staff regarding catheter management, use of antibiotics, hair removal, and placement of head dressings, which led to a $>50 \%$ reduction in VAIs in each study. ${ }^{13}$

The influence of duration of catheterization on VAI rates continues to be a topic of clinical debate. The initial study to examine the attributable risk of duration of external ventricular catheterization to VAI was conducted by Mayhall et al. in 1984; the authors found an increase in VAIs, especially after Day 5, and found rates of VAI as high as $21 \%, 37 \%$, and $42 \%$ by Days 8,10 , and 11 , respectively. ${ }^{42}$ However, nearly 20 years later, a retrospective study by Park et al. analyzed 595 patients with prolonged EVD catheterization and found that infection rates rose until Day 4 and then plateaued. Their overall infection rate of $8.6 \%$ was similar to rates previously published, suggesting that prolonged catheterization $>4$ days may not significantly increase the chance of infection. ${ }^{47}$

Similarly, in a retrospective analysis of 584 patients with severe TBI who underwent EVD placement, VAI rates steadily increased until Day 10, after which they plateaued..$^{29}$ Clinically, the prolonged use of EVDs may be indicated for pathologies such as TBI and aneurysmal $\mathrm{SAH}$, in which cases infection is a more probable complication, likely influenced by the underlying pathology. Although the removal of EVDs as soon as possible is a well-accepted practice, ultimately, therapeutic benefits of the continued use of EVDs should be weighed against the risk of infection.

\section{Postprocedural Hemorrhage}

Hemorrhage associated with EVD placement can potentially cause devastating and irreversible injury, with re-

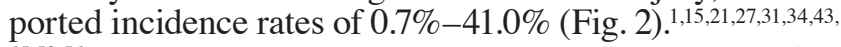
${ }_{45,50,56}$ Miller and Tummala described a case series of 482 patients who received an EVD for management of their intracranial hemorrhage; $21.6 \%$ of patients had a postprocedural hemorrhage present on images obtained after ventriculostomy. The average volume of the tract hemorrhage was $1.96 \pm 6.48 \mathrm{~cm}^{3}$, and 2 patients had hemorrhages that required intervention. In this series, decreased platelet levels on admission and an increasing number of EVD placement attempts correlated with an increased risk of hemorrhage. ${ }^{43}$

Similarly, Gardner et al. found that $41 \%$ of 188 EVDs placed resulted in evidence of hemorrhage on postplace-

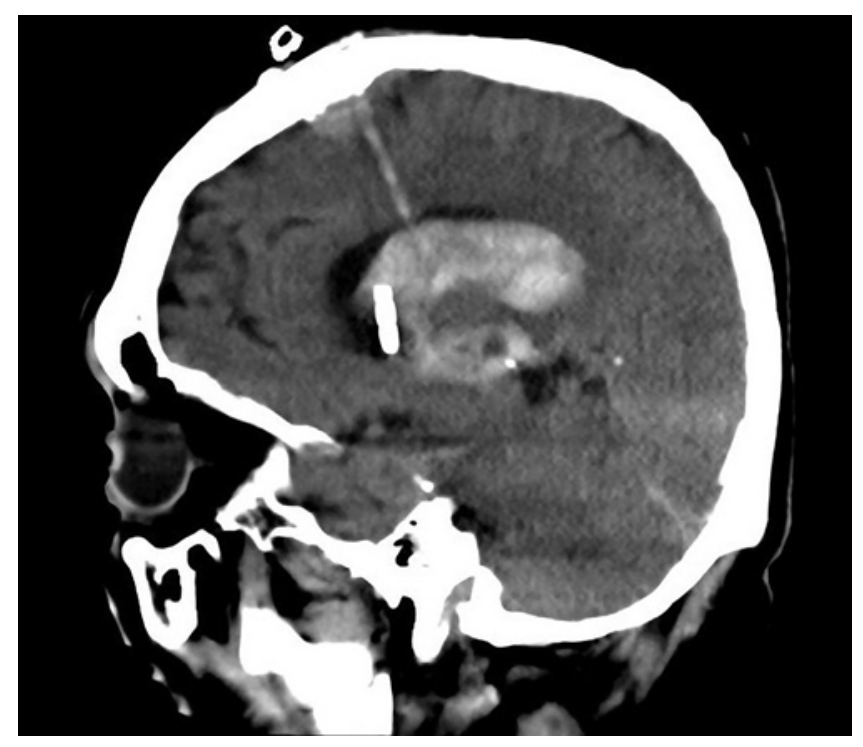

FIG. 2. Noncontrast head CT oblique sagittal section showing ventriculostomy tract hemorrhage, intraventricular hemorrhage, and ventricular enlargement after removal of an EVD from a patient with a severe TBI. The CT scan was prompted by a decline in mental status within several hours of EVD removal. After CT scanning, a new EVD was placed on the contralateral side.

ment CT images, of which 20 patients had hemorrhages $>15 \mathrm{ml}$ and 1 patient required evacuation of a subdural hematoma. ${ }^{21}$ In contrast, other analyses have reported post-EVD-placement hemorrhage rates of $1 \%-8 \%$, with clinically significant or symptomatic hemorrhages occurring in $<1 \%$ of patients. ${ }^{1,27,34,47}$ In a meta-analysis of 16 studies and 2428 ventriculostomies, Bauer et al. found a $7 \%$ cumulative hemorrhage rate, with a $0.8 \%$ rate of clinically significant hemorrhage. ${ }^{3}$

Likewise, in another meta-analysis by Binz et al. of 1790 EVD placements, an overall hemorrhage rate of $5.7 \%$ was reported, with clinically significant hemorrhage occurring in $<1 \%$ of patients. ${ }^{7}$ The varied rates of hemorrhage observed following ventriculostomy (Table 3) are probably related to different definitions of hemorrhage, duration of surveillance, indication for placement, treatment of coagulopathies, and variable practice patterns.

The literature regarding rates of hemorrhage following ICPM placement is not well characterized. A retrospective study of 288 patients with EVD and/or ICPM placement found hemorrhages in 2 patients after EVD placement and in 1 patient after ICPM placement, with none of the 3 hematomas requiring surgical evacuation..$^{16}$ In another retrospective study of 549 patients managed with Codman Microsensor (Codman Neuro, Codman \& Shurtleff, Inc.) ICPMs, 27 patients were found to have a hematoma, 26 of which were $<1 \mathrm{~cm}^{3}$, with 1 that was $8 \mathrm{~cm}^{3} \cdot{ }^{35}$ GelabertGonzález et al. have published the largest retrospective series to date of 1000 patients with ICPMs. Interestingly, in their study, of 87 patients with at least 1 abnormal coagulation parameter, 7 had a catheter-related hemorrhage (8\%) compared with 18 hemorrhages among the 903 patients $(2 \%)$ with normal coagulation parameters. ${ }^{22}$ This relatively higher risk of hemorrhage in patients with ab- 
TABLE 3. Incidence of ventriculostomy-related hemorrhages

\begin{tabular}{|c|c|c|c|c|}
\hline Authors \& Year & Type of Study & No. of Cases & Hemorrhage Rate & Comments \\
\hline Guyot et al., 1998 & Retrospective & 536 & $\begin{array}{l}\text { EVD hemorrhage rate } 3.3 \% \text {, Camino ICPM } \\
\text { hemorrhage rate } 0.9 \% \text {, other devices } 0 \%\end{array}$ & \\
\hline Maniker et al., 2006 & Retrospective & 160 & Hemorrhage rate $32.5 \%$, symptomatic in $2.5 \%$ & Majority $<4 \mathrm{~cm}$ \\
\hline Sussman et al., 2014 & Retrospective & 69 & Hemorrhage rate $31.9 \%$, symptomatic in $1.4 \%$ & Average vol $0.66 \pm 1.06 \mathrm{~cm}^{3}$ \\
\hline Gardner et al., 2009 & Retrospective & 188 & $\begin{array}{l}\text { Hemorrhage rate in ICU } 44.3 \% \text {, hemorrhage } \\
\text { rate in OR } 34.8 \%\end{array}$ & Trace $51.9 \%,>15 \mathrm{ml}$ in $10.6 \%$ \\
\hline Dimitriou et al., 2016 & Retrospective & 288 & $\begin{array}{l}\text { EVD hemorrhage rate } 1.1 \% \text {, ICPM hemor- } \\
\text { rhage rate }<1 \%\end{array}$ & \\
\hline $\begin{array}{l}\text { Miller \& Tummala, } \\
2017\end{array}$ & Retrospective & 482 & $\begin{array}{l}\text { Postplacement hemorrhage rate } 21.6 \% \text {, } \\
\text { postremoval hemorrhage rate } 22.5 \%\end{array}$ & $\begin{array}{l}\text { Mean vol } 1.96 \pm 6.48 \mathrm{~cm}^{3} \text {, mean vol } 8.25 \\
\quad \pm 20.34 \mathrm{~cm}^{3}\end{array}$ \\
\hline Koskinen et al., 2013 & Retrospective & 549 & Codman microsensor hemorrhage rate $0.04 \%$ & $96 \%$ were $<1 \mathrm{~cm}^{3}$ \\
\hline $\begin{array}{l}\text { Gelabert-González } \\
\text { et al., } 2006\end{array}$ & Retrospective & 1000 & Camino fiberoptic hemorrhage rate $0.025 \%$ & $\begin{array}{c}w / \geq 1 \text { abnormal coagulation parameter } 8 \% \text {, } \\
\text { w/ normal coagulation parameters } 2 \%\end{array}$ \\
\hline Bauer et al., 2011 & Meta-analysis & 2428 & Hemorrhage rate $7 \%$, symptomatic in $0.8 \%$ & \\
\hline Binz et al, 2009 & Meta-analysis & 1790 & Hemorrhage rate $5.7 \%$, symptomatic in $<1 \%$ & \\
\hline Dey et al., 2015 & Systematic review & 3079 & $\begin{array}{l}\text { Hemorrhage rates } 0 \%-41 \% \text {, symptomatic } \\
\text { rates } 0 \%-14.6 \%\end{array}$ & \\
\hline
\end{tabular}

normal coagulation parameters highlights an important clinical factor to consider when placing ICPMs.

The need for administration of chemical prophylactic agents against venous thromboembolism (VTE) after EVD placement presents a challenge in the management of neurocritically ill patients, for whom physicians must balance the risk of intracranial hemorrhage with the benefit of preventing a deep venous thrombosis (DVT) or pulmonary embolism. In a retrospective review of 99 patients who received 111 EVDs, there was no significant difference in EVD-associated hemorrhagic events between patients who were administered VTE chemoprophylaxis within 24 hours of admission (early) and those who were administered VTE chemoprophylaxis later than 24 hours after admission (delayed) $(\mathrm{p}=0.731) .{ }^{57}$ Importantly, starting chemoprophylaxis within 24 hours was not associated with a decrease in the number of DVTs found in patients who were clinically suspected to have DVT.

At our institution, Dengler and colleagues retrospectively studied 155 patients with severe TBI who underwent intracranial monitoring and did not find a significant association between the use of DVT chemoprophylaxis and worsening of traumatic intracranial hemorrhage. ${ }^{14}$ In this study, the median time to starting DVT prophylaxis was 3.6 days. As opposed to the previous study in patients with TBI, a retrospective study of 46 patients with aneurysmal SAH showed an increased rate of tract hemorrhage and an increased hematoma volume in patients who received subcutaneous unfractionated heparin within 4 hours of EVD placement compared with those who had received it 4-24 hours after EVD placement.$^{20}$ In light of this, further clinical trials are needed to determine the appropriate interval for beginning VTE chemoprophylaxis after placement of invasive intracranial monitors.

In patients with aneurysmal disease who present with intraventricular hemorrhage and/or SAH causing acute hydrocephalus, EVD placement is a key component of their management. Furthermore, during the course of their hospitalization, these patients often require antiplatelet agents or heparinization for treatment of their aneurysmal pathology. Relevantly, in a retrospective analysis of patients who were receiving antiplatelet agents, anticoagulation for DVT prophylaxis, or intraprocedural anticoagulation, Leschke et al. studied hemorrhage rates in patients who were undergoing coil embolization for ruptured cerebral aneurysms who had EVDs placed within 24 hours of admission for acute hydrocephalus. They found a minimal, nonsignificant increase in rates of hemorrhage in patients who were receiving antiplatelet agents, anticoagulation for DVT prophylaxis, or intraprocedural anticoagulation. ${ }^{37}$ Further characterization of the effects of various antiplatelet and anticoagulant agents on the timing of intracranial catheter placement is needed to help inform practitioners of safe and effective practices.

In turn, as practitioners, we are often faced with patients with invasive intracranial monitoring devices who require therapeutic anticoagulation for the treatment of pulmonary emboli, blunt cerebrovascular injuries, or for the secondary prevention of stroke in patients with significant risk factors (e.g., mechanical valve replacements, cardiac thrombus, and so on). In instances when the riskto-benefit ratio favors therapeutic anticoagulation, we recommend using intravenous unfractionated heparin without bolus dosing and closely monitoring the patient in a neurological intensive care setting with serial bloodwork, CT imaging, and serial neurological examinations.

\section{Misplacement of EVDs}

Optimal placement of EVDs is important to ensure adequate drainage and to obtain accurate measurements of ICP waveforms in neurocritically ill patients. Although ventriculostomy is the most commonly performed neurosurgical procedure, there is no standard technique for placement of the catheters. Misplacement of EVDs with a freehand 

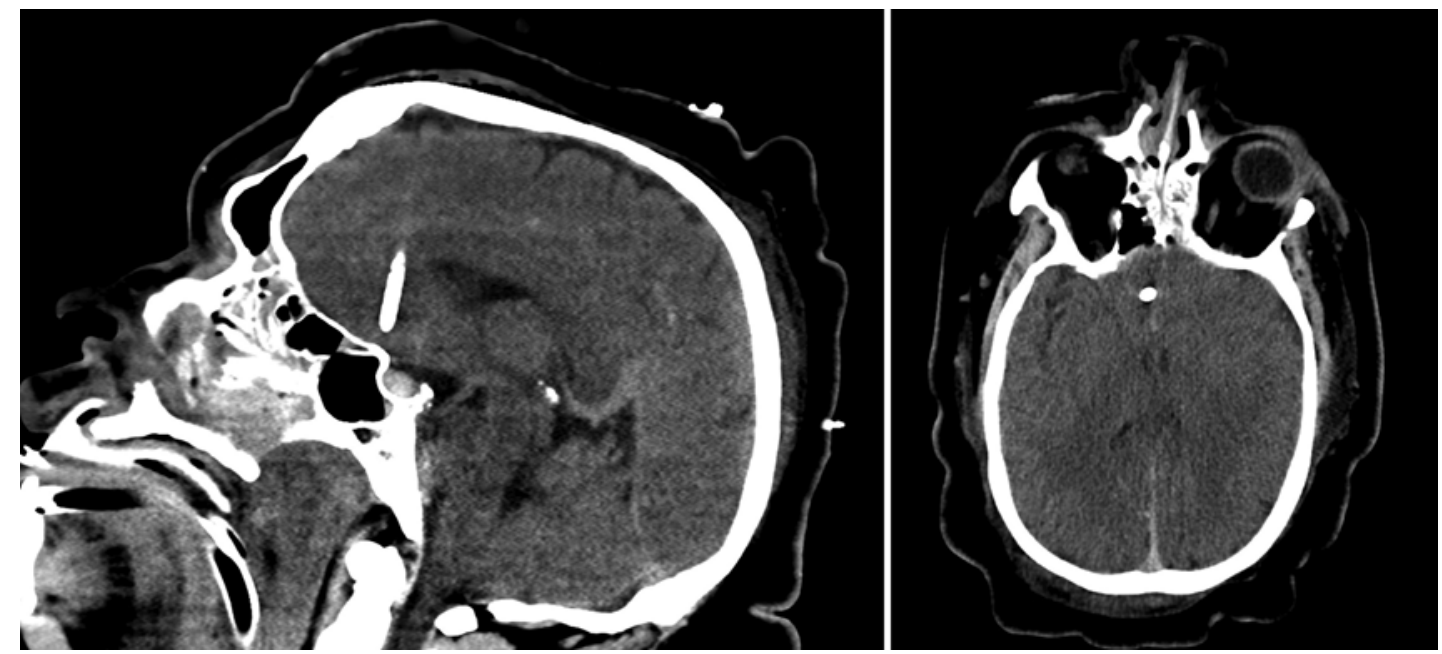

FIG. 3. Noncontrast sagittal (left) and axial (right) head CT scans demonstrating anterior misplacement of an EVD, with the tip projecting in the interhemispheric fissure.

technique is a common concern, with reported rates ranging from $8 \%$ to $45 \%$ depending on intracranial pathology and operator technique, experience, and skill., 11,31,34,46,53

The initial location for bur hole placement at Kocher's point varies in practice, as was found in 7 studies that aimed to assess accuracy of EVD placement. Instructions for its location in the sagittal axis were described as 10-12 $\mathrm{cm}$ posterior to the nasion, $10 \mathrm{~cm}$ posterior to the supraorbital ridge, or $1 \mathrm{~cm}$ in front of the coronal suture, with the directions in the coronal axis described as $2-3 \mathrm{~cm}$

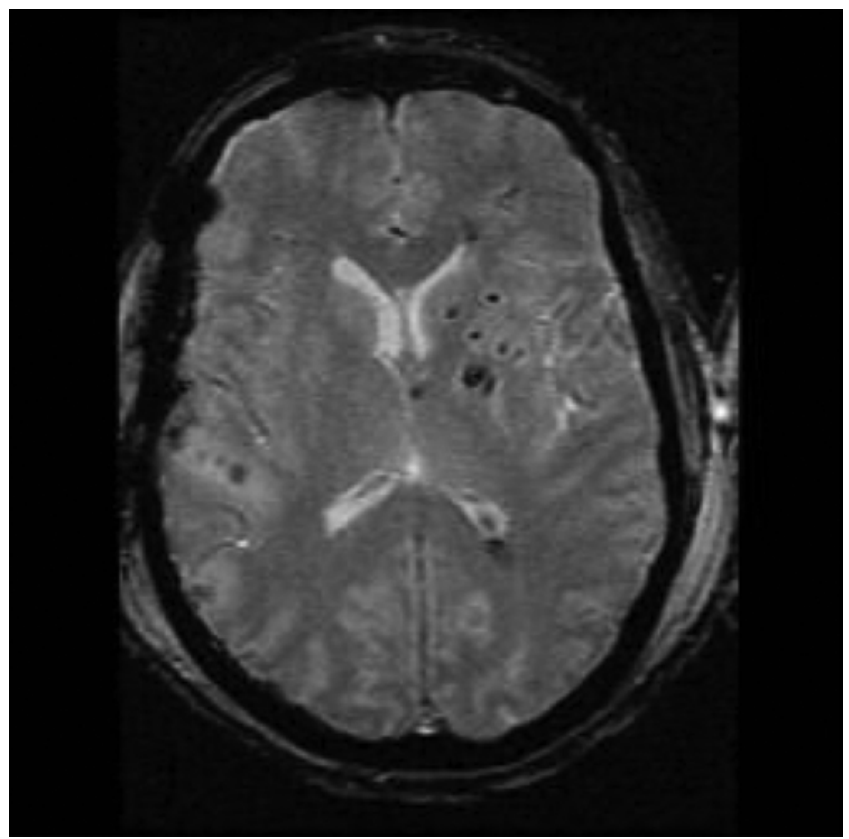

FIG. 4. Axial susceptibility-weighted MR image demonstrating several punctuate regions of subcortical injury from errant EVD passes. Reprinted from Neurocritical Care Management of the Neurosurgical Patient, William Ares, Ramesh Grandhi, Bradley J. Molyneaux, David Okonkwo: Placement and complications of intracranial monitors and lumbar drains, pp 429-437, 2018, with permission from Elsevier. from midline or in relation to the midpupillary line.,17,31, 34,36,46,53 The most common method for placement involves the location of Kocher's point, with the trajectory dictated by aligning the catheter in intersecting planes passing through the ipsilateral tragus and medial canthus (Fig. 3).

Alternatively, alignment of the catheter can be achieved using Dandy's principle of using a trajectory perpendicular to the skull. Failed attempts to cannulate the ventricle most often occur due to aiming lateral to the ventricle (Fig. 4), which highlights the importance of drilling the bur hole properly such that the trajectory of the catheter is not limited. In situations where the calvarial bone is especially thick, an improper bur hole trajectory can prevent ventricular cannulation entirely. Preparation via examination of underlying anatomy and pathology on imaging can help guide placement and should be routine practice.

Many groups have attempted to evaluate and compare the accuracy of EVD placement using different methods and practices. In 2008, Kakarla et al. proposed a new grading system examining 2 factors: location of the catheter tip, and functional status of the catheter for analyzing the accuracy of EVD placement. Grade 1 indicates optimal placement of the catheter tip in the ipsilateral frontal horn or third ventricle, Grade 2 indicates functional placement in the contralateral frontal horn or lateral ventricle, and Grade 3 indicates suboptimal placement in eloquent tissue despite functional status. After applying their novel grading system retrospectively to a series of 346 patients with EVDs placed freehand at the bedside, Grade 1 placement was achieved in $77 \%$ of patients, Grade 2 in $10 \%$, and Grade 3 in 13\%. The authors noted that suboptimal placement occurred most frequently in patients with TBI and in those with a midline shift on images. ${ }^{34}$

In 2015, Foreman and colleagues retrospectively applied the grading system of Kakarla et al. to evaluate 138 patients who underwent EVD placement in the intensive care unit (ICU) versus the operating room (OR) setting and revealed that a higher rates of optimally placed $(67.7 \%$ vs $55.6 \%)$ and suboptimally placed (6.5\% vs $2.2 \%$ ) EVDs occurred with placement in the ICU. As would be expected, place- 
TABLE 4. Accuracy and misplacement of EVDs

\begin{tabular}{|c|c|c|c|c|}
\hline Authors \& Year & Type of Study & $\begin{array}{l}\text { No. of } \\
\text { Cases }\end{array}$ & Technique & Comments \\
\hline \multicolumn{5}{|l|}{ Accuracy of placement } \\
\hline Abdoh et al., 2012 & Retrospective & 56 & Freehand & Angular variation $\pm 5^{\circ}$ in $50 \%$ in coronal plane and in $40 \%$ in sagittal plane \\
\hline Ehtisham et al., 2009 & Retrospective & 29 & Freehand & $82.8 \%$ placed in ipsilat anterior horn, foramen of Monro, or 3rd ventricle \\
\hline Huyette et al., 2008 & Retrospective & 98 & Freehand & $56.1 \%$ successfully placed in ipsilat lat ventricle or foramen of Monro \\
\hline Foreman et al., 2015 & Retrospective & 138 & Freehand & $\begin{array}{l}67.7 \% \text { vs } 55.6 \% \text { successful placement in ICU vs OR, } 6.5 \% \text { vs } 2.2 \% \text { required } \\
\text { revision }\end{array}$ \\
\hline Saladino et al., 2009 & Retrospective & 212 & Freehand & $12.3 \%$ misplaced, $2.4 \%$ required revision \\
\hline Kakarla et al., 2008 & Retrospective & 346 & Freehand & $77 \%$ Grade 1 placements, $10 \%$ Grade 2 placements, $13 \%$ Grade 3 placements \\
\hline \multicolumn{5}{|l|}{ Use of adjunct methods } \\
\hline Bergdal et al., 2013 & Retrospective & 154 & $\begin{array}{l}\text { Tunnelated vs } \\
\text { bolt }\end{array}$ & $\begin{array}{l}69.1 \% \text { vs } 49.1 \% \text { optimal placement in bolt vs tunnelated, decreased need for } \\
\text { revision }\end{array}$ \\
\hline Jensen et al., 2016 & Retrospective & 272 & Tunneled vs bolt & $40 \%$ vs $6.5 \%$ need for revision, tunnel vs bolt, respectively \\
\hline O'Leary et al., 2000 & Prospective & 49 & $\begin{array}{l}\text { Freehand vs } \\
\text { Ghajar }\end{array}$ & $\begin{array}{l}\text { Fewer catheters crossed midline w/ Ghajar ( } 4 \% \text { vs } 20.8 \% \text { ), fewer no. of passes } \\
\text { ( } 1.1 \text { vs } 1.5 \text { passes) }\end{array}$ \\
\hline AlAzri et al., 2017 & Prospective & 54 & $\begin{array}{r}\text { Freehand vs } \\
\text { navigation }\end{array}$ & $\begin{array}{l}\text { Grade } 1 \text { placement more frequent ( } 94.7 \% \text { vs } 57.1 \% \text { ), suboptimal placement } \\
\text { less frequent ( } 5.3 \% \text { vs } 42.9 \%) \text {, fewer number of passes (1.16 vs } 1.63 \\
\text { passes) w/ navigation }\end{array}$ \\
\hline Mahan et al., 2013 & Prospective & 34 & $\begin{array}{l}\text { Stereotactic im- } \\
\text { age guidance }\end{array}$ & $94.1 \%$ Grade 1 placements, $5.9 \%$ Grade 2 placements \\
\hline Krötz et al., 2004 & Prospective & 52 & CT guided & $100 \%$ placement; decreased times to placement \& to transfer to ICU \\
\hline
\end{tabular}

ment in the ICU was most commonly performed for head trauma, whereas OR placements occurred for less emergent cases or when placement occurred in conjunction with other neurosurgical procedures (i.e., aneurysm clipping).$^{18}$

Concerns about suboptimal placement of EVDs have led practitioners to develop adjunct methods aimed at improving accuracy. Several centers use a custom-made metal bolt for placement of the catheter to reduce the chance of dislodgment or displacement, especially in patients who are confused and/or combative. For example, Bergdal et al. compared the accuracy of tunnelated versus bolt-connected placement of EVDs in a retrospective series of 147 patients who required 154 EVDs. The authors concluded that the use of a bolt system significantly improved accuracy $(p=0.023)$ and decreased the need for catheter revision $(\mathrm{p}=0.006){ }^{6}$

Similarly, Jensen et al. found that complications requiring reinsertion were more frequent in patients with tunneled EVDs compared with a cohort of patients with boltconnected EVDs $\left(40 \%\right.$ vs $6.5 \%$; p < 0.001). ${ }^{33}$ The Ghajar Guide is a rigid tripod that allows for physical guidance of the catheter at an orthogonal trajectory. In a randomized, prospective study in 49 patients by O'Leary et al., which compared the efficacy of EVD placement using the Ghajar Guide versus conventional placement, use of the Ghajar Guide decreased the number of catheters that crossed the midline (1 vs 5 catheters) and required fewer passes for successful ventricular cannulation $(1.1 \pm 0.3$ vs $1.5 \pm 0.9$ passes; $\mathrm{p}=0.07) .{ }^{46}$

The use of adjunctive image guidance is more commonly being used for placement of EVDs. A prospective study that compared EVDs placed with a frameless computer-based neuronavigation guidance system with a ret- rospective cohort of patients with TBI with EVDs placed freehand found that neuronavigation nearly doubled the likelihood of achieving placement in the ipsilateral lateral ventricle $(94.7 \%$ vs $57.1 \%$; $p=0.009)$ and required statistically significantly fewer passes $(1.16 \pm 0.38$ vs $1.63 \pm 0.86$ passes; $\mathrm{p}=0.018){ }^{2}$

Likewise, Mahan et al. found that stereotactic imageguided placement of EVDs in the ICU setting allowed for near perfect catheter placement; ironically, this occurred at the cost of 40 additional minutes to achieve successful ventricular cannulation compared with historical cohorts. ${ }^{40}$ The increased time that is required to use image guidance may not be the best management option for patients with impending cerebral herniation issues; however, if time allows, an imaging guidance system may improve the likelihood of optimal placement.

In a novel system designed by Krötz et al., CT-guided percutaneous ventriculostomies were performed in 52 prospective patients with a $100 \%$ cannulation rate. In their analysis, the authors compared their cohort with a retrospective cohort of patients who received conventional, freehand ventriculostomy placement and found that the procedure time $(20 \pm 12$ vs $45 \pm 11$ mins $)$ and time to transfer to ICU $(69 \pm 34$ vs $138 \pm 34$ mins $)$ were significantly decreased $(\mathrm{p}<0.05)$. Although there are probably multiple confounding factors affecting the differences in these times, the perfect success rate of this method is attractive for improving patient care. ${ }^{36}$

Indications for EVD placement are often emergent in nature, and any delay in successful catheterization increases the risks of morbidity and mortality in this patient population. Although various techniques may provide greater accuracy and decrease the need for replacement or 
revision of the catheter, they often come with an associated cost-delayed time to placement, which allows for more brain damage to occur before intervention (Table 4). Specifically, placement of EVDs using image guidance, either at the bedside or in the OR, may help increase optimal positioning, but not necessarily functionality, of EVDs. Ultimately, the decision regarding the location and method used for EVD placement should be made on a case-bycase basis and account for the acuity of the patient, the underlying pathology, and known risks.

\section{Conclusions}

Invasive intracranial monitoring has changed considerably since its origin in the 18th century, but there are still considerable risks of infection, hemorrhage, and misplacement. The uncertainties regarding an appropriate definition for VAIs, infection prophylaxis, timing of DVT chemoprophylaxis, and ideal method of placement of intracranial monitors highlight the need for further welldesigned trials on the subject of limiting complications associated with invasive intracranial monitoring.

\section{References}

1. Abdoh MG, Bekaert O, Hodel J, Diarra SM, Le Guerinel C, Nseir R, et al: Accuracy of external ventricular drainage catheter placement. Acta Neurochir (Wien) 154:153-159, 2012

2. AlAzri A, Mok K, Chankowsky J, Mullah M, Marcoux J: Placement accuracy of external ventricular drain when comparing freehand insertion to neuronavigation guidance in severe traumatic brain injury. Acta Neurochir 159:1399-1411, 2017

3. Bauer DF, Razdan SN, Bartolucci AA, Markert JM: Metaanalysis of hemorrhagic complications from ventriculostomy placement by neurosurgeons. Neurosurgery 69:255-260, 2011

4. Baum GR, Hooten KG, Lockney DT, Fargen KM, Turan N, Pradilla G, et al: External ventricular drain practice variations: results from a nationwide survey. J Neurosurg [epub ahead of print January 13, 2017; DOI: 10.3171/2016.9.JNS16367]

5. Bekar A, Gören S, Korfali E, Aksoy K, Boyaci S: Complications of brain tissue pressure monitoring with a fiberoptic device. Neurosurg Rev 21:254-259, 1998

6. Bergdal O, Springborg JB, Holst AV, Hauerberg J, Way S, Breum P, et al: Accuracy of tunnelated vs. bolt-connected external ventricular drains. Clin Neurol Neurosurg 115:19721975, 2013

7. Binz DD, Toussaint LG III, Friedman JA: Hemorrhagic complications of ventriculostomy placement: a meta-analysis. Neurocrit Care 10:253-256, 2009

8. Blomstedt GC: Results of trimethoprim-sulfamethoxazole prophylaxis in ventriculostomy and shunting procedures. A double-blind randomized trial. J Neurosurg 62:694-697, 1985

9. Carney N, Totten AM, O'Reilly C, Ullman JS, Hawryluk GWJ, Bell MJ, et al: Guidelines for the management of severe traumatic brain injury, fourth edition. Neurosurgery 80:6-15, 2017

10. Chatzi M, Karvouniaris M, Makris D, Tsimitrea E, Gatos C, Tasiou A, et al: Bundle of measures for external cerebral ventricular drainage-associated ventriculitis. Crit Care Med 42:66-73, 2014

11. Citerio G, Signorini L, Bronco A, Vargiolu A, Rota M, Latronico N: External ventricular and lumbar drain device infections in ICU patients: a prospective multicenter Italian study. Crit Care Med 43:1630-1637, 2015
12. Dandy WE: Ventriculography follow the injection of air into the cerebral ventricles. Ann Surg 68:5-11, 1918

13. Dasic D, Hanna SJ, Bojanic S, Kerr RSC: External ventricular drain infection: the effect of a strict protocol on infection rates and a review of the literature. Br J Neurosurg 20:296300, 2006

14. Dengler BA, Mendez-Gomez P, Chavez A, Avila L, Michalek J, Hernandez B, et al: Safety of chemical DVT prophylaxis in severe traumatic brain injury with invasive monitoring devices. Neurocrit Care 25:215-223, 2016

15. Dey M, Stadnik A, Riad F, Zhang L, McBee N, Kase C, et al: Bleeding and infection with external ventricular drainage: a systematic review in comparison with adjudicated adverse events in the ongoing Clot Lysis Evaluating Accelerated Resolution of Intraventricular Hemorrhage Phase III (CLEAR-III IHV) trial. Neurosurgery 76:291-301, 2015

16. Dimitriou J, Levivier M, Gugliotta M: Comparison of complications in patients receiving different types of intracranial pressure monitoring: a retrospective study in a single center in Switzerland. World Neurosurg 89:641-646, 2016

17. Ehtisham A, Taylor S, Bayless L, Klein MW, Janzen JM: Placement of external ventricular drains and intracranial pressure monitors by neurointensivists. Neurocrit Care 10:241-247, 2009

18. Foreman PM, Hendrix P, Griessenauer CJ, Schmalz PGR, Harrigan MR: External ventricular drain placement in the intensive care unit versus operating room: evaluation of complications and accuracy. Clin Neurol Neurosurg 128:94100,2015

19. Fried HI, Nathan BR, Rowe AS, Zabramski JM, Andaluz N, Bhimraj A, et al: The insertion and management of external ventricular drains: an evidence-based consensus statement: a statement for healthcare professionals from the Neurocritical Care Society. Neurocrit Care 24:61-81, 2016

20. Gard AP, Sayles BD, Robbins JW, Thorell WE, Surdell DL: Hemorrhage rate after external ventricular drain placement in subarachnoid hemorrhage: time to heparin administration. Neurocrit Care [epub ahead of print], 2017

21. Gardner PA, Engh J, Atteberry D, Moossy JJ: Hemorrhage rates after external ventricular drain placement. J Neurosurg 110:1021-1025, 2009

22. Gelabert-González M, Ginesta-Galan V, Sernamito-García R, Allut AG, Bandin-Diéguez J, Rumbo RM: The Camino intracranial pressure device in clinical practice. Assessment in a 1000 cases. Acta Neurochir (Wien) 148:435-441, 2006

23. Gopinath SP, Cherian L, Robertson CS, Narayan RK, Grossman RG: Evaluation of a microsensor intracranial pressure transducer. J Neurosci Methods 49:11-15, 1993

24. Gopinath SP, Robertson CS, Contant CF, Narayan RK, Grossman RG: Clinical evaluation of a miniature straingauge transducer for monitoring intracranial pressure. Neurosurgery 36:1137-1141, 1995

25. Gozal YM, Farley CW, Hanseman DJ, Harwell D, Magner M, Andaluz N, et al: Ventriculostomy-associated infection: a new, standardized reporting definition and institutional experience. Neurocrit Care 21:147-151, 2014

26. Gray WP, Palmer JD, Gill J, Gardner M, Iannotti F: A clinical study of parenchymal and subdural miniature straingauge transducers for monitoring intracranial pressure. Neurosurgery 39:927-932, 1996

27. Guyot LL, Dowling C, Diaz FG, Michael DB: Cerebral monitoring devices: analysis of complications. Acta Neurochir Suppl 71:47-49, 1998

28. Harrop JS, Sharan AD, Ratliff J, Prasad S, Jabbour P, Evans JJ, et al: Impact of a standardized protocol and antibioticimpregnated catheters on ventriculostomy infection rates in cerebrovascular patients. Neurosurgery 67:187-191, 2010

29. Holloway KL, Barnes T, Choi S, Bullock R, Marshall LF, Eisenberg HM, et al: Ventriculostomy infections: the effect 
of monitoring duration and catheter exchange in 584 patients. J Neurosurg 85:419-424, 1996

30. Honda H, Jones JC, Craighead MC, Diringer MN, Dacey RG, Warren DK: Reducing the incidence of intraventricular catheter-related ventriculitis in the neurology-neurosurgical intensive care unit at a tertiary care center in St Louis, Missouri: an 8-year follow-up study. Infect Control Hosp Epidemiol 31:1078-1081, 2010

31. Huyette DR, Turnbow BJ, Kaufman C, Vaslow DF, Whiting BB, Oh MY: Accuracy of the freehand pass technique for ventriculostomy catheter placement: retrospective assessment using computed tomography scans. J Neurosurg 108:88-91, 2008

32. Jacobs DG, Westerband A: Antibiotic prophylaxis for intracranial pressure monitors. J Natl Med Assoc 90:417-423, 1998

33. Jensen TS, Carlsen JG, Sørensen JC, Poulsen FR: Fewer complications with bolt-connected than tunneled external ventricular drainage. Acta Neurochir (Wien) 158:1491-1494, 2016

34. Kakarla UK, Kim LJ, Chang SW, Theodore N, Spetzler RF: Safety and accuracy of bedside external ventricular drain placement. Neurosurgery 63 (1 Suppl 1):ONS162-ONS167, 2008

35. Koskinen LOD, Grayson D, Olivecrona M: The complications and the position of the Codman MicroSensor ${ }^{\mathrm{TM}}$ ICP device: an analysis of 549 patients and 650 sensors. Acta Neurochir (Wien) 155:2141-2148, 2013

36. Krötz M, Linsenmaier U, Kanz KG, Pfeifer KJ, Mutschler W, Reiser M: Evaluation of minimally invasive percutaneous CT-controlled ventriculostomy in patients with severe head trauma. Eur Radiol 14:227-233, 2004

37. Leschke JM, Lozen A, Kaushal M, Oni-Orisan A, Noufal M, Zaidat $\mathrm{O}$, et al: Hemorrhagic complications associated with ventriculostomy in patients undergoing endovascular treatment for intracranial aneurysms: a single-center experience. Neurocrit Care 27:11-16, 2017

38. Lewis A, Wahlster S, Karinja S, Czeisler BM, Kimberly WT, Lord AS: Ventriculostomy-related infections: The performance of different definitions for diagnosing infection. Br J Neurosurg 30:49-56, 2016

39. Lozier AP, Sciacca RR, Romagnoli MF, Connolly ES Jr: Ventriculostomy-related infections: a critical review of the literature. Neurosurgery 51:170-182, 2002

40. Mahan M, Spetzler RF, Nakaji P: Electromagnetic stereotactic navigation for external ventricular drain placement in the intensive care unit. J Clin Neurosci 20:1718-1722, 2013

41. Maniker AH, Vaynman AY, Karimi RJ, Sabit AO, Holland B: Hemorrhagic complications of external ventricular drainage. Neurosurgery 59 (4 Suppl 2):ONS419-ONS425, 2006

42. Mayhall CG, Archer NH, Lamb VA, Spadora AC, Baggett JW, Ward JD, et al: Ventriculostomy-related infections. A prospective epidemiologic study. N Engl J Med 310:553 559, 1984

43. Miller C, Tummala RP: Risk factors for hemorrhage associated with external ventricular drain placement and removal. J Neurosurg 126:289-297, 2017

44. Murthy SB, Moradiya Y, Shah J, Hanley DF, Ziai WC: Incidence, predictors, and outcomes of ventriculostomy-associated infections in spontaneous intracerebral hemorrhage. Neurocrit Care 24:389-396, 2016

45. Naff N, Williams MA, Keyl PM, Tuhrim S, Bullock MR, Mayer SA, et al: Low-dose recombinant tissue-type plasminogen activator enhances clot resolution in brain hemorrhage: the intraventricular hemorrhage thrombolysis trial. Stroke 42:3009-3016, 2011

46. O'Leary ST, Kole MK, Hoover DA, Hysell SE, Thomas A, Shaffrey CI: Efficacy of the Ghajar Guide revisited: a prospective study. J Neurosurg 92:801-803, 2000

47. Park P, Garton HJL, Kocan MJ, Thompson BG: Risk of infection with prolonged ventricular catheterization. Neurosurgery 55:594-601, 2004

48. Poblete R, Zheng L, Raghavan R, Cen S, Amar A, Sanossian N, et al: Trends in ventriculostomy-associated infections and mortality in aneurysmal subarachnoid hemorrhage: data from the Nationwide Inpatient Sample. World Neurosurg 99:599-604, 2017

49. Pople I, Poon W, Assaker R, Mathieu D, Iantosca M, Wang E, et al: Comparison of infection rate with the use of antibioticimpregnated vs standard extraventricular drainage devices: a prospective, randomized controlled trial. Neurosurgery 71:6-13, 2012

50. Rebuck JA, Murry KR, Rhoney DH, Michael DB, Coplin WM: Infection related to intracranial pressure monitors in adults: analysis of risk factors and antibiotic prophylaxis. $\mathbf{J}$ Neurol Neurosurg Psychiatry 69:381-384, 2000

51. Reyes MM, Munigala S, Church EL, Kulik TB, Keyrouz SG, Zipfel GJ, et al: Comparing external ventricular drains-related ventriculitis surveillance definitions. Infect Control Hosp Epidemiol 38:574-579, 2107, 2017

52. Rosegay H: The Krause operations. J Neurosurg 76:10321036, 1992

53. Saladino A, White JB, Wijdicks EFM, Lanzino G: Malplacement of ventricular catheters by neurosurgeons: a single institution experience. Neurocrit Care 10:248-252, 2009

54. Srinivasan VM, O'Neill BR, Jho D, Whiting DM, Oh MY: The history of external ventricular drainage. J Neurosurg 120:228-236, 2014

55. Stoikes NF, Magnotti LJ, Hodges TM, Weinberg JA, Schroeppel TJ, Savage SA, et al: Impact of intracranial pressure monitor prophylaxis on central nervous system infections and bacterial multi-drug resistance. Surg Infect (Larchmt) 9:503-508, 2008

56. Sussman ES, Kellner CP, Nelson E, McDowell MM, Bruce SS, Bruce RA, et al: Hemorrhagic complications of ventriculostomy: incidence and predictors in patients with intracerebral hemorrhage. J Neurosurg 120:931-936, 2014

57. Tanweer O, Boah A, Huang PP: Risks for hemorrhagic complications after placement of external ventricular drains with early chemical prophylaxis against venous thromboembolisms. J Neurosurg 119:1309-1313, 2013

58. Tunkel AR, Hasbun R, Bhimraj A, Byers K, Kaplan SL, Scheld WM, et al: 2017 Infectious Diseases Society of America's clinical practice guidelines for healthcare-associated ventriculitis and meningitis. Clin Infect Dis 64:701-706, 2017

59. Zabramski JM, Whiting D, Darouiche RO, Horner TG, Olson J, Robertson C, et al: Efficacy of antimicrobial-impregnated external ventricular drain catheters: a prospective, randomized, controlled trial. J Neurosurg 98:725-730, 2003

\section{Disclosures}

The authors report no conflict of interest concerning the materials or methods used in this study or the findings specified in this paper.

\section{Author Contributions}

Conception and design: all authors. Drafting the article: all authors. Critically revising the article: all authors. Reviewed submitted version of manuscript: all authors. Approved the final version of the manuscript on behalf of all authors: Grandhi.

\section{Correspondence}

Ramesh Grandhi, Department of Neurosurgery, University of Texas Health San Antonio, 7703 Floyd Curl Dr., San Antonio, TX 78229. email: grandhi@uthscsa.edu. 